\title{
e-Engineering through e-Business Change Management
}

\author{
Colin G. Ash and Janice M. Burn
}

Edith Cowan University

\begin{abstract}
This paper reports on a longitudinal study of e-business change management in ERP enabled organisations. Twenty organisations agreed to participate in the study and data was collected through ongoing e-dialogue and face to face interviews over a two year period. An analysis of the findings led to the adoption of a model proposing various antecedents to successful e-business change management in ERP environments. Multiple case studies with varying dimensions of e-business scope are described in context of this model and a detailed case study of an organisation with a highly innovative project is used to illustrate the facilitators that lead to e-business project success.
\end{abstract}

\section{INTRODUCTION}

Numerous papers have been written about e-business and how this concept will change the way companies do business, characterised by rapid exchange of information within a virtual network of customers and suppliers working together to create value-added processes (Ticoll et al, 1998; El Sawy et al, 1999; Wigand and Benjamin, 1998; Jansen et al, 1999; Burn and Barnett, 2000). However, little information is available on how to successfully integrate e-Business projects with ongoing ERP implementations or already productive ERP systems (Hesterbrink, 1999; Holland and Light, 1999).). As more and more established organisations realise that they need to form alliances with their customers, partners and suppliers over the Internet, e-business integration with ERP systems becomes a critical issue (Gable, 1998; Markus and Tanis, 2000).

This combination of technologies offers established companies the opportunity to build interactive relationships with their partners and suppliers, improve efficiency and extend their reach, all at a very low cost. For example, GE estimates to save $\$ 500$ million to $\$ 700$ million of its purchasing costs over three years and cut purchasing cycles by as much as 50\% (Hesterbrink, 1999: p3). The Norwegian 
company Statoil, processes more than 350,000 invoices annually, and awards over 40,000 contracts through web enabled ERP commerce. The company expects a considerable improvement in the ratio of invoices to orders as well as a tangible contribution to revenue (SAP, 1999; Venkatraman et al, 1999). Eventually, both companies expect to buy the majority of their purchases through Web-based bidding systems. Faced with such e-business innovations companies are looking for effective solutions to marry the two technologies for strategic advantage. Inevitably this will have a major impact on their employee workforce, the processes they have to perform and their skill requirements. The workforce has had to embrace a new culture as a knowledge based community with far more flexible work roles. Increasingly, we are seeing the large traditional organisation breaking up and the emergence of new, networked organisational forms in which work is conducted by temporary teams that cross organisation lines. (Markus, Manville and Agres, 2000).

In this new climate, organisations have to learn new approaches to managing a workforce of knowledge workers, yet little information is available on how to implement this successfully and how to ensure more effective personnel performance as a result. Drucker (1998) suggests that the traditional role of managers telling workers what to do is no longer viable and instead managers must direct people as if they were unpaid volunteers, tied to the organisation by commitment to its aims and purposes and often expecting to participate in its governance.

This paper reports on the findings from multiple case studies of e-business projects in ERR enabled organisations. The key findings from each case study are captured into a theoretical framework for e-business change management. A detailed analysis of one major project using this framework illustrates the suitability of using this as a model for evaluating success factors. The case presents a recently implemented e-business project in personnel management within the energy services division of Engineer.com, at one of its overseas locations. The company uses SAP $\mathrm{R} / 3$ as its global ERP solution. Rather than emphasising technological issues the focus is now clearly on cultural change and organisational performance issues (Pereira, 1999) and the factors that empower employees to support large-scale change. In particular it looks at the motivational factors influencing employees to initiate change in the face of these new realities and the implications for management in the learning organisation.

\section{E-BUSINESS AND ERP}

Venkatraman and Henderson, (1998) have defined an e-business model for the learning organisation that promotes harmony over three vectors - customer/market interaction, asset sourcing and knowledge leverage supported by a strong 
information technology platform. They see this as the virtual organising model for the $21^{\text {st }}$ Century and as such a management strategy in itself.

Figure 1 gives a view of an organisation using an Enterprise Resource Planning (ERP) system such as SAP, as an integrated system to enable knowledge management across the three vectors of the organisation.

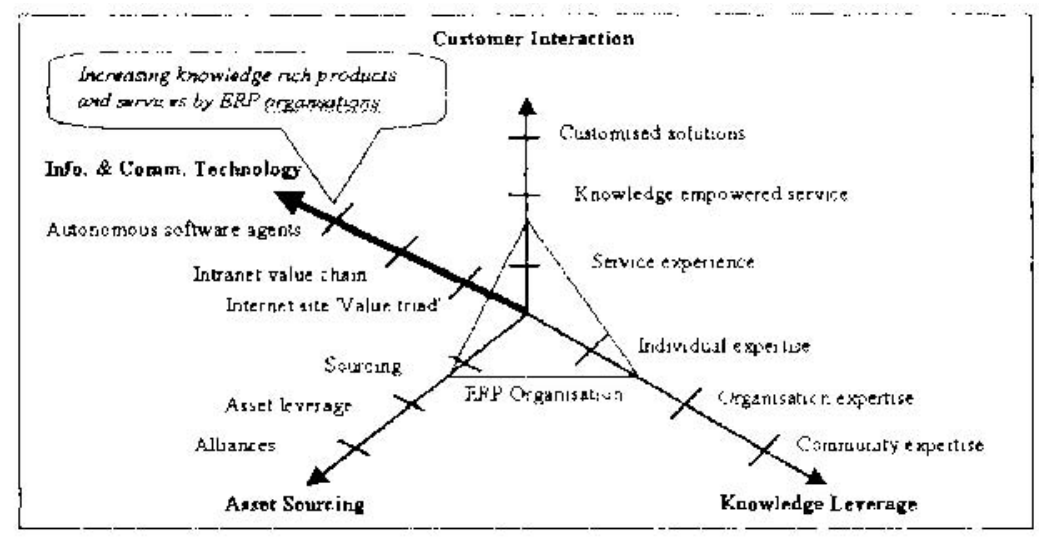

Figure 1. e-Business and ERP

(i) Customer interaction (B2C) refers to the extent to which an organisation virtually interacts with the market defined at three levels of greater virtual progression. (ii) Asset sourcing (B2B) refers to competency leveraging from varying complexity. (iii) Knowledge leverage (B2E) refers to access to expertise beyond the organisation.

This model acted as the initial basis for investigating how far along the three vectors organisations had implemented integrated e-business through ERP systems.

Kalakota, (1999) states "the creation and implementation of an e-business project is inextricably linked to the management of change" (Kalakota et al, 1999; $\mathrm{p}$ $60)$.

This requires systematic attention to learning processes, organisational culture, technology infrastructure, people and systems thinking. Hesterbrink (1999) further emphasises the importance of alignment of those dimensions with respect to ERP and e-Business implementations. e-Business change is defined here as an organisational initiative to design an e-business project.

"to achieve significant (breakthrough) improvements in performance (eg quality, responsiveness, cost, flexibility, satisfaction, shareholder value, and other critical e-business measures) through changes in relationships between management, information, technology, organisational structure, and people" (Guha, et al, 1997: p 121). 
Planning and managing such systems requires an integrated multi-dimensional approach across the e-business and the development of new business process models (Kumar and Crook, 1999; Scheer and Habermann, 2000).

Therefore, in any examination of outcomes, consideration should be given to (a) the environmental conditions for change and (b) the ability of the organisation to manage change in those conditions. Outcomes of e-business change can be measured at various levels of the broad complex phenomenon of any e-ERP project. Previous studies by Guha et al (1997) indicate successful e-business projects should tend to have facilitators over many dimensions but also failure is most likely to occur where too little consideration has been given to key factors such as cultural readiness or change management.

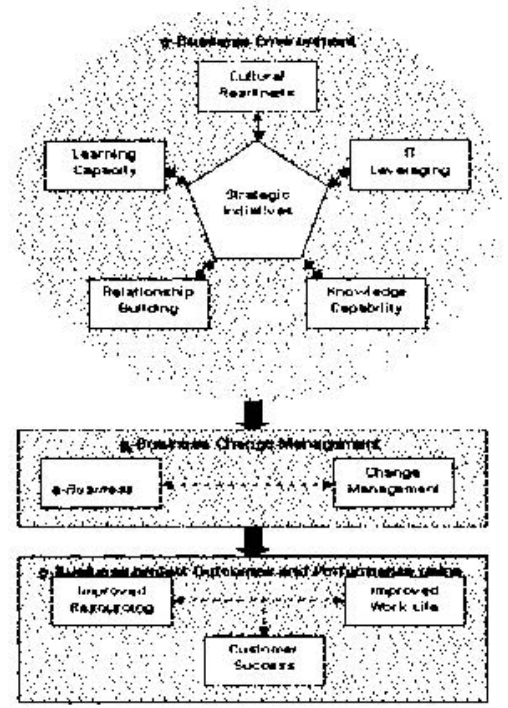

Figure 2: Theoretical Framework of e-Business Change Management (Adapted from Guha et al, 1997)

"Any significant business process change requires a strategic initiative where top managers act as leaders in defining and communicating a vision of change. The organisational environment, with ready culture, a willingness to share knowledge, balanced network relationships, and a capacity to learn, should facilitate the implementation of prescribed e-business management and change management.

Both of these are requisite for customer success and ultimately in achieving measurable and sustainable competitive performance" ( $p$ 121). 
Increasingly, organisations are realising that importance must be given to improving quality of work-life issues. If effectively managed, employees should ultimately be more productive in their work tasks and better able to serve customers, suppliers, and business partners. The key constructs that can be probed here are: gaps between effectiveness expectations (goals) and actual performance improvements, eg employee work satisfaction, efficient resourcing, and customer interaction (Venkatraman and Henderson, 1998).

The model in Figure 2 was used in this study to identify facilitators and inhibitors of successful e-business change. The relationships presented in the framework are based on relevant work in organisational change, strategic management innovation, and information systems. The general thesis of the framework is adapted from Guha's et al, (1997) work on "business process change management"

\section{BACKGROUND TO STUDY}

\subsection{Case Selection}

"Embedded" multiple case-study analysis was chosen to investigate the research questions concerning the complex phenomenon of e-business change projects. Embedded approaches enlist the use of multiple units of analysis; (1) the company (strategy), (2) the project team, (3) the project. This triangulation attempts to validate primary data. The case-studies selection criterion required a major ebusiness project, which had organisational implications. Also, as the focus was on studying antecedents to organisational performance, a homogeneous set of projects (having similar initiatives) with variance across cases but with the same outcome measures - cost, responsiveness, flexibility, satisfaction, shareholder value, and other e-business metrics - was required

To identify the sites, a search using secondary literature, web sites, and SAP related industry consultants were contacted to identify major e-ERP projects (Ash, 2000). There were three stages to the investigation: the initial stage focused on ten local (West Australian) organisations and the subsequent development of mini-case studies; stage two was expanded to include a further ten overseas organisations (with a more restricted selection criteria) and the development of an additional seven minicases; stage three was a return visit to eight of the organisations to develop full case histories. In each case a senior IT/SAP project manager was contacted for interviews. 


\subsection{Investigations of Overseas SAP Sites}

In November 1999, initial interviews in ten sites, were conducted in person by visiting each organisation at their headquarters. Senior e-business project managers were questioned about "the benefits and barriers arising from extending their R/3 business processes onto the Internet" (Ash, 2000). Sites were selected using a set of e-Business activity selection criteria:

- It should involve a major e-Business project with organisational implications.

- The project should have been completed.

- At some point the project should have an expected breakthrough performance.

- The project should focus on cross-functional business activities.

- Initial assessment of outcomes should be unambiguous (Guha et al, 1997).

A repeat visit to each of eight sites was performed in June/July 2000 to collect the detailed information for this study, using the following protocol. In each case the focal point of contact was the most senior level IT/SAP project manager. Multiple archival documents, as well as many conversations via e-mail. A qualitative structured interview questionnaire was used during the second visits to collect primary data for the study from eight (8) SAP worldwide sites (Table 1).

Table 1: All Case Organisations Interviewed

\begin{tabular}{|c|c|c|c|c|c|c|c|c|}
\hline 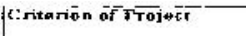 & Bank & Biutech & TCharity & Cump & Employ & 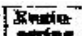 & s şite $\bar{c}$ & Socinty \\
\hline l.Mvar besaness propece & 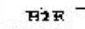 & $\overline{\pi 2} \bar{P}$ & $\bar{p}$ & $\frac{\sin x}{\sin }$ & BaEs & when & B2B:C & $\overline{\mathbf{E x} C}$ \\
\hline 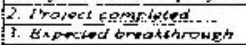 & $\begin{array}{c}\text { Eucally } \\
\text { Yel }\end{array}$ & $\begin{array}{l}\text { Yos } \\
\text { Yes }\end{array}$ & $\begin{array}{l}\text { Sthe } \\
\text { Yex } \\
\text { Yex }\end{array}$ & $\begin{array}{l}\text { Yre } \\
\text { Yes }\end{array}$ & $\begin{array}{l}Y=x \\
Y=A\end{array}$ & $\operatorname{Tan}_{\text {Tax }}$ & $\begin{array}{l}Y_{e s} \\
Y_{\text {ev }}\end{array}$ & $\begin{array}{l}\text { Yes } \\
\text { Yes }\end{array}$ \\
\hline 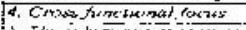 & Yes & Yes & $Y=5$ & $Y=5$ & $Y=s$ & $x_{n=x}$ & $Y \circ z$ & $\begin{array}{l}\text { Yes } \\
\text { M.5: }\end{array}$ \\
\hline 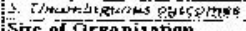 & $Y(x)$ & $\frac{\text { Yres }}{\text { Modien }}$ & $Y_{\mathrm{cs}}$ & $\frac{Y}{c s}$ & 3150 & $y=$ & Yre & $\begin{array}{c}N= \\
\text { Sinta-13 }\end{array}$ \\
\hline Signific anra ol Trajnet & Mretistm & H.gh & Fus iste & Fixle & i.never & thes. & High & - \\
\hline
\end{tabular}

Eg Case 1. - Bank [Large] Business-to-Employee (B2E) "Employee Intranet" Case 2. - Biotech [Medium] Business-to-Business (B2B) "e-Procurement" Case 3. - Society [Small] Business-to-Customer (B2C) "Online Ordering"

In Table 1, Engineer.com stands out from the other cases as highly innovative because of its global potential and project content. For Engineer.com, employee resourcing for offshore oil and gas projects is expensive, complex, and dynamic (Baark, 1999). Managers need to make informed decisions when skilled worker schedules change. To optimise worker overtime requires access to employment records in real-time, at remote locations, under critical circumstances, and knowledge of all local employment. There are significant penalties in Norway for employing foreign workers over an agreed time quota. 


\section{EVALUATING AN E-ERP SUCCESS (CASE 4)}

\section{Engineer.com - "Management Reporting and Personnel System"}

This in-house Intranet using R/3 personnel data, is an incremental HR Internet initiative for project management of offshore skilled agency workers. Its application has proven to be a major tool for supporting decision making for minimising labour costs. It has been expanded to include a computer hardware tracking system. With the aid of computer graphics this Intranet systems provides a simple "walk-up" user interface for casual users, for example project managers who have little or no training on the R/3 HR sub-system. Further, the use of mobile phone technology has enabled access to the intranet by the project managers whilst offshore.

Data was collected using a structured questionnaire that extracted three levels of detail (Table 2). By analysing the data and comments captured from the interviews, a summary of comments was first constructed. These comments helped focus on the individual contributions of the components of the research or business framework. Each component of the framework was rated as having a positive (+ve) or negative (-ve) contribution towards the Intranet project. In some cases, both positive and negative contributions were found from one component variable.

Table 2: Summary of Findings for each component of the e-Business Framework

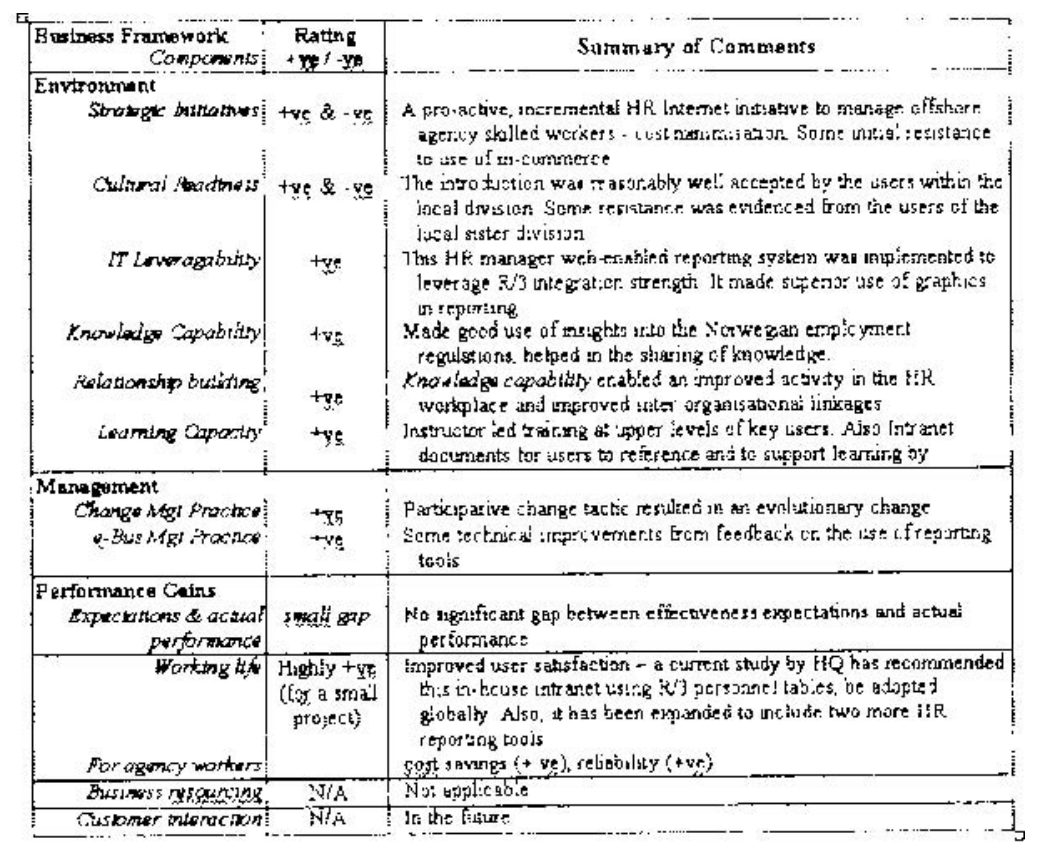

Key: + ve $=$ facilitator, - ve $=$ inhibitor; $+\&-=$ facilitator $\&$ inhibitor 
The results given in Table 2 show that a high overall level of success was achieved. The column of ratings draws attention to the importance of having positive contribution from all the components (synergy) for the project to be successful (Guha et al, 1997). However, two components were rated as having both a positive and negative influences. To understand these summarised findings, a more in depth discussion follows for each of the three main dimensions of e-business change - the change environment, the management of change, and the outcomes and performance gains.

\subsection{Change Environment}

Strategic Initiatives This IT innovation sprang from the insights of one of the company's local HR professional staff members. This is in spite of autocratic decision making from the central administration. It was observed that poor project management of the number days worked for each agency employee could cause excessive labour cost. The local government regulations for offshore labour have very strict penalties.

Cultural Readiness In the project, the HR staff project team showed a desire to initiate change. The change agent was the practical leadership of the HR staff.. "We are very proud of this Intranet solution."

According to Mintzberg and Westley, (1992), a visionary leader is a single leader who influences change. For Engineer.com the leadership showed inspiration for the development of a practical solution that overcame management obstacles. As senior management remarked after the implementation. "This Internet enabled ERP environment will serve to facilitate global collaboration throughout the company".

There remained, however, the partner organisation professional rivalry. A culture of resistance to accept change was introduced from a key partner.

Network Relationships For Engineer.com, the project demonstrated positive cooperation with the local agency government and the beginnings of crossfunctional cooperation. As IT management stated "Our Web-base solution assists the most casual user with global, personalised, and secure access to our corporate information on demand".

Learning Capacity In the project, learning by doing and learning from others helped improve the professional end-user IT skills. This enabled project managers to adapt to a quality decision making scenario.

IT Leveragability and Knowledge Capability For Engineer.com, the project demonstrated positive local leadership, superior IT design for improved learning, and business-to-employee communication, but with some collaborative resistance. To overcome resistance to change, each must be aligned (along with the enabling technology) to the strategic initiatives to overcome resistance to change (Hesterbrink, 1999). 


\section{2 e-Business Change Management}

Change Management In the e-business management practice, the pattern of change was reported to be a participative change tactic resulting in an evolutionary change. This was viewed as a "waterfall" progression of change, starting with an alleviation of dissatisfaction by HR professionals and eventually arriving at a well managed process:

alleviation of dissatisfaction,

$\Rightarrow$ vision for change,

L evolutionary change tactics, well-managed process for change

e-Business Management The team based structure involving HR and IT personnel was felt to be critical to the success of the project and allowed for the growth and transfer of knowledge among the team members. The use of graphics in combination with the web tools and techniques also had positive influence on the use by casual professional users.

\subsection{Outcomes and Performance gains}

Outcomes It was reported that from the outset the project showed an improvement in one of the outcome constructs - the quality of work life (QWL). However, within the area of performance gains, improved business resourcing was seen as most significant (positive). As a measure of its success and/or acceptance, the Intranet solution was expanded to include the IT department's computer hardware tracking system.

Performance Gains The performance gains were achieved from two sources; labour cost savings in hiring agency contract employees, and access to reliable (realtime) employee data via mobile technology. The project enabled efficiency gains from minimising of offshore labour costs, and effectiveness gains from optimising opportunity labour costs. For example, when the offshore work was delayed or ahead of schedule, the on site project managers had mobile phone access to online real-time data for deciding on the optimal allocation of agency workers. This type of cost savings through operational efficiencies of labour resourcing, can be compared to those cost savings (efficiencies) in the e-procurement case studies.

\subsection{Case Summary}

This case study shows how one small group within a large global organisation succeeded in making the HR business processes of their ERP systems available over the Internet. The human resources (HR) staff at one location were motivated to initiate an e-business project and to form a team with IT staff and user project managers to develop a suitable system. A "personnel management intranet" was 
developed and by leveraging the power of graphics and Internet technology extended the reach of the ERP (HR) business processes, for casual users. The knowledge contribution from all members of the team enabled them to implement this project leading to significant improvement in organisational performance. The primary beneficiaries were the offshore project managers, who needed access to the HR employee tables for personnel management and gained this through the innovative use of mobile technology. The result was one of considerable costs saving and greatly improved staff resourcing through improved decision making by the project managers when working off shore.

The intrinsic motivation and self-management of autonomous knowledge within the development team played an important role in the successful implementation. The emphasis was very much more on collective performance rather than individual but at the same time development and maintenance of personal and professional reputations was a significant driver.

Interestingly, while the project was rated highly successful there was strong opposition from their partner operations to implement the same system and this came from the counterpart HR staff who had not been exposed to the participative development process. Further, the organisational management were lukewarm in their support initially, viewing the proposed system as a threat to a strongly centralised control culture. Once the results broke down their initial resistance, management "assumed" responsibility for the success and leadership for global implementation.

"We are beginning to recognise the potential benefits of leveraging our SAP R/3 business processes through the new Web-based environment"

\section{CONCLUSIONS}

An established research framework of e-Business change is used to identify the factors for success of this e-business project within an ERP environment. The results confirm that a successful project was found to have facilitators in all components of the business framework, including the change environment and project management. Further there is the implication that; the least successful e-business projects will have inhibitors in both dimensions, especially in the area of cultural readiness and change management. In this case study conflict arose between local project management initiatives versus a centralised autocratic global ERP deployment. This highlights the need to encourage the balancing of conflicting organisational knowledge, when contemplating the adoption of e-business solutions.

The case presented was used to test the suitability of an established research framework for gathering evidence to identify the factors for success of an e-business project. In order to avoid an original IT-centric position, we emphasise the importance of managing the change of e-business projects. This research framework 
was chosen as a methodology for its ability to examine complex phenomena. It is seen as evolutionary in nature, and was content driven. It is primarily a diagnostic tool for identifying factors contributing to success of new business models. It is not seen as a prognostic tool. It specifically explores the areas related to the successful learning organisation where the key issues remain as people oriented business issues.

In the future as e-business activities become common place, corporate portals for empowering employees will be considered as a competitive necessity. The next wave of economic advantage lies in revenue generation from new business opportunities in other business-to-business models, such as business-to-consumer for customer satisfaction. These are complex problems that can never be solved with technology alone. They require leadership, appropriate problem solving skills, lots of hard work and executive commitment and a culture that embraces the ideals of the learning organisation (a team and community oriented work process). The organisational design, learning environment, and human-to-human communication and collaboration must be aligned to the enabling technology. "One should always keep in mind the balance between people, business processes, and technology" (Carlson, 1995). In a labour force of cross-functional virtual teams management will be more about motivation and governance may be largely a question of selfregulation rather than traditional managerial control. IT professionals may well be better equipped for this change given the large "community of practice" with a strong, shared culture of technical professionalism and their extended use of technology for communication and decision making.

\section{REFERENCES}

Ash, C.G. (2000) An e-Commerce Model for Extending ERP Systems onto the Internet: An Australian Perspective, In Proceedings of the International Conference of Enterprise Information Systems, ICEIS'2000, Stafford, UK 4-7 July.

Baark, E, (1999) Engineering Consultancy: An Assessment of IT-enabled International delivery of services, Technology Analysis \& Strategic Management, March, Vol 11, No 1 pp 55-74

Boey, P. Grasso, M. Sabatino, G. Sayeed, I. (1999) Architecting eBusiness Solutions, Vol II No. 7 [http://www.cutter.com/consortium/freestuff/dcar9907.html]

Burn, J. M. and Barnett, M. L. (2000) Emerging Virtual Models for Global e-commerce world wide retailing in the e-grocery business. Special Millennium Issue of Journal of Global Information Technology Management, Vol 3, No. 1, pp 18-32.

Carlson, DA (1995) Harnessing the Flow of Knowledge, [http://www.dimensional.com/ dcarlson/papers/KnowFlow.htm]

Drucker, P. F. (1998) Management's New Paradigms, Forbes, Oct. 5, pp 152-177.

EL Sawy, O. A., Malhotra, A., Gosain, S. AND Young, K. M. (1999) IT-Intensive Value Innovation in the Electronic Economy: Insights from Marshall Industries. MIS Quarterly, Vol 23, No 3, pp 305-335. 
Gable, G. G. (1998). Large Packaged Software: a neglected technology? Editorial, Journal of Global Information Management 6(3), pp3-4.

Guha, S. Grover, V. Kettinger, W.J. Eng, J.T.C. (1997) Business Process Change and Organisational Performance: Exploring an Antecedent Model, Journal of Management Information Systems, Vol. 14, No1, pp. 119-154.

Hesterbrink, C. (1999) e-Business and ERP: Bringing two Paradigms together, PriceWaterhouse Coopers, Sept.

Holland, C. P. and Light, B. (1999). Generic Information Systems Design Strategies. Americas Conference on Information Systems, Milwaukee, August.

Jansen, W., Steenbakkers, W. AND Jagers, H. Electronic Commerce and Virtual Organisations. Special Issue of eJov (Vol. 1, No. 1) pp 54-68.

Kalakota, R. Robinson, M. (1999), e-Business: Roadmap for Success, Addison-Wesley Longman, MA, USA

Kumar, R. L. and Crook, C. W. A. (1999) Multi-Disciplinary Framework for the Management of Interorganisational Systems, The Data Base for Advances in Information Systems, Vol. 30 (1).

Markus, M. L., Manville, B. and Agres, C. E. (2000). What makes a virtual organisation work? Sloan Management Review, Vol. 42 (1), pp 13-26.

Markus, M. L. C., and Tanis, C (2000). Multisite ERP Implementations. Communications of the ACM 43(40, pp 42-46.

Mintzberg, H. Westley, F. (1992) Cycles of Organisational Change, Strategic Mangement Journal, 13, pp. 39-59

Pereira, R.E. (1999) Resource View Theory Analysis of SAP as a Source of Competitive Advantage for Firms, The Database for Advances in Information Systems, Winter 1999, Vol. 30, No. 1; 38-46

SAP (1999) SAP B2B Procurement at Statoil (1999) No 64, p. 18 [http://www.sap.com/sapinfo.net/industries/]

Scheer, A. W. and Habermann, F. (2000) Making ERP a Success. Communications of the ACM 43(4), pp 57-61.

Ticoll, D., Lowry, A. and Kalakota, R. (1998) Joined at the Bit, in Blueprint to the Digital Economy creating wealth in the era of e-business Don Tapscott, Alex Lowy and David Ticoll, McGraw-Hill

Venkatraman, N. Henderson, J.C. (1998), Real strategies for Virtual Organising, Sloan Management Review, Fall '98, 33-48.

Venkatraman, N, Tanriverdi, H, Stokke, P (1999). It it working? Working from home at Statoil, Norway. Europen Management Journal, 17 (5), pp 513-531.

Wigand, R.T., and Benjamin, R.I. (1995). Electronic Commerce: Effects on electronic markets, Journal of Computer-Mediated Communication [On-line], 1 (3), http://www.ascusc.org/jcmc/vol1/issue3/wigand.html 